\title{
Implementasi Canny Edge Detection Pada Aplikasi Pendeteksi Jalur Lalu Lintas
}

\author{
Ratna Salkiawati*, Allan D Alexander, Hendarman Lubis \\ Fakultas Ilmu Komputer, Program Studi Ilmu Informatika, Universitas Bhayangkara Jakarta Raya, Jakarta, Indonesia \\ Email: 1,*ratna_tind@dsn.ubharajaya.ac.id, ${ }^{2}$ allan@ubharajaya.ac.id, ${ }^{3}$ hendarman.lubis@dsn.ubharajaya.ac.id \\ Email Penulis Korespondensi: ratna_tind@dsn.ubharajaya.ac.id
}

\begin{abstract}
Abstrak- Berdasarkan laporan kecelakaan lalu lintas di temukan bahwa ada 41.771 (Empat puluh satu ribu tujuh ratus tujuh puluh satu) kejadian disebabkan oleh faktor pengemudi yang tidak tertib. (POLRI, 2018). Salah satu ketidaktertiban ini dengan mengendarai kendaraan bermotor diluar jalur lalu lintas. Pada penelitian ini peneliti mengembangkan computer vision dengan menggunakan metode Canny Edge Detection. Tahapan pada Canny Edge Detection adalah proses image acquisition, proses image segmentation, dan proses image understanding. Penelitian ini bertujuan mengembangkan aplikasi dengan menggunakan computer vision untuk memperingatkan pengemudi yang tidak tertib berlalu lintas atau meningkatkan kewaspadaan pengendara kendaraan bermotor dengan cara mendeteksi kondisi jalur yang dilalui oleh pengemudi tersebut. Diharapkan penelitian ini memberikan rasa aman bagi pengendara kendaraan bermotor, serta menyediakan aplikasi yang diharapkan mampu meningkatkan kewaspadaan pengemudi guna menghindari kecelakaan lalu lintas.
\end{abstract}

Kata Kunci: Computer Vision; Sensor; Image Processing; Lalu Lintas; Keamanan

\begin{abstract}
Based on the traffic accident report, it was found that there were 41,771 (Forty-one thousand seven hundred and seventy-one) incidents caused by disorderly drivers. (POLRI, 2018). One of these disorders is by driving a motorized vehicle outside the traffic lane. In this study, researchers developed computer vision using sensor methods and image processing. The stages in computer vision are the image acquisition process, the image segmentation process, and the image understanding process. This study aims to develop an application using computer vision to warn drivers of disorderly traffic or to increase the alertness of motorized vehicle drivers by detecting the condition of the driver's path. It is hoped that this research will provide a sense of security for motorized vehicle drivers, as well as provide applications that are expected to increase driver awareness to avoid traffic accidents.
\end{abstract}

Keywords: Computer Vision; Sensor, Image Processing; Traffic; Safety

\section{PENDAHULUAN}

Berdasarkan laporan kecelakaan lalu lintas yang di publikasi KORLANTAS POLRI pada tahun 2018 menunjukan bahwa angka kecelakaan lalu lintas di Indonesia sebesar 91.371 (sembilan puluh satu ribu tiga ratus tujuh puluh satu) kejadian yang disebabkan oleh faktor pengemudi dan dalam data tersebut di temukan bahwa ada 41.717 (empat puluh satu ribu tujuh ratus tujuh belas) kejadian disebabkan oleh faktor pengemudi yang tidak tertib (POLRI, 2018)

Banyak upaya yang dilakukan untuk mengurangi atau mencegah kecelakaan dengan menggunakan berbagai macam system, antara lain Forward Collision Warning (FCW), Left/Right Cross Collision Warning (CTW), On Coming Traffic Warning (OTW), Red Light Warning (RW) dan Stop Sign Warning (SW Invalid source specified. Pengembangan sistem tersebut menggunakan berbagai macam metode sensor, dan salah satu sensor yang digunakan adalah kamera yang terhubung dengan computer vision system, implementasi dari computer vision selama ini bertujuan untuk keperluan; system tranportasi cerdas, kendaraan otonom dan Advanced Driver Assistance System.

Prinsip kerja dari computer vision terdiri dari beberapa tahapan yaitu; Images Acquisition, Processing, Analyzing; dimana kamera akan menangkap representasi objek lalu di tangkap oleh sensor optik lalu diubah menjadi data digital, dan data-data tersebut akan diproses untuk di Analisa Invalid source specified. Salah satu teknik yang menjadi bagian proses dalam computer vision adalah Hough Tranform dimana proses ini akan memudahkan sebuah sistem untuk mendeteksi sebuah garis dalam sebuah gambar binari Invalid source specified. dan dalam computer vision proses analyzing menggunakan berbagai jenis algoritma antara lain; K-Mean, algoritma linear, algoritma iterative dan lain-lain (Szeliski, 2010).

Beberapa penelitian telah menggunakan computer vision system diantaranya adalah: penelitian yang berjudul "Computer Vision Untuk Pengenalan Obyek Pada Peluncuran Roket Kendaraan Tempur", hasil dari penelitian tersebut dengan metode image processing melalui proses morfologi citra untuk pengenalan objek dilanjutkan dengan proses perhitungan kecepatan tank yang melintas menghasilkan informasi waktu yang diperlukan dari target/sasaran menuju titik penghancuran [1]. Pada penelitian "Perancangan Sistem Pendeteksi Kepadatan Lalu Lintas Menggunakan Image Processing Dengan Metode Background Subtraction Pada Sikomolintas", menghasilkan data kepadatan dan status lalu lintas, mengendalikan pewaktuan simulasi lampu lalu lintas berdasarkan data kepadatan yang ada, serta dapat diintegrasikan dengan SIKOMOLINTAS [2] . Pada penelitian "Aplikasi Pendeteksi Rambu Lalu-Lintas Menggunakan Operator Sobel dan Metode Hamming", dengan adanya aplikasi ini diharapkan dapat mempermudah user dalam mengetahui fungsi dari rambu-rambu yang terdapat di jalan raya [3]. Pada penelitian "Lane Detection and Tracking For Intelligent Vehicles: A Survey", hasil dari penelitian ini adalah bahwa pada beberapa model yang digunakan untuk Lane Detection and Tracking harus 
JURNAL MEDIA INFORMATIKA BUDIDARMA

Volume 5, Nomor 1, Januari 2021, Page 164-169

ISSN 2614-5278 (media cetak), ISSN 2548-8368 (media online)

Available Online at https://ejurnal.stmik-budidarma.ac.id/index.php/mib

DOI 10.30865/mib.v5i1.2502

mempertimbangkan beberapa faktor, seperti garis lalu lintas dan rambu lalu lintas, serta mempertimbangkan sisi kompleksitas dan effisiensi dari algoritma dan juga big data [4]. Penelitan lainnya "A Study on Detection Method of Vehicle Based on Lane Detection for a Driver Assistance System Using a Camera on Highway" hasil penelitianya adalah algoritma bekerja pada rata rata 42 milliseconds pada setiap frame dengan resolusi 3.30 intel CPU [5]. Penelitian "An All-weather Lane Detection System Based on Simulation Interaction Platform” [6]. Penelitian "A Method of Lane Edge Detection Based on Canny Algorithm" [7]. Penelitian "Real-Time Lane Detection-Based Line Segment Detection" [8]. Penelitian "Vision Based Vehicle Monitoring at Road Intersections" [9]. Penelitian "A Study Of Lane Detection Techniques And Lane Departure System" [10], penelitian "Adaptive Image Edge Detection Algorithm Based on Canny Operator" [11]. Penelitian "Deteksi Jenis Kendaraan di Jalan Menggunakan OpenCV" [12]. Penelitian " Implementasi Metode Canny Dan Sobel Untuk Mendeteksi Tepi Citra" [13]. Penelitian "Implementasi Metode Deteksi Tepi Canny Pada Objek Sebagai Model Keamanan Aplikasi Pada Smartphone Android" [14]. Dan pada penelitian "Implementasi Deteksi Tepi Canny Dengan Transformasi Powerlaw Dalam Mendeteksi Stadium Kanker Serviks” [15].

Dari beberapa penelitian terdahulu banyak yang menggunakan algotritma canny sebagai dasar untuk mendeteksi jalur lalu lintas dan penelitian ini akan menggunakan algoritma tersebut untuk membangun sebuah system pendeteksi jalur lalu lintas untuk membantu meningkatkan kewaspadaan pengendara kendaraan bermotor.

\section{METODOLOGI PENELITIAN}

\subsection{Tahapan Penelitian}

Langkah-langkah yang dilakukan dalam penelitian ini yaitu identifikasi masalah, dengan melakukan survey dan melihat data kecelakaan lalu lintas yang terjadi pada 2 tahun kebelakang. Pengumpulan data, dimana pada tahapan ini akan dikumpulkan data berupa data video kondisi lalu lintas jalan, dan pada tahapan ini telah didapatkan video kondisi lalu lintas jalan bebas hambatan (jalan Tol) dalam kota Jakarta sebagai data untuk membangun model dan mengujinya. Langkah selanjutnya adalah menggambil sampel data berupa gambar diam (still image) untuk diproses dan pada tahapan inilah algoritma canny edge detection akan diimplementasikan guna mendeteksi objek berupa garis lalu lintas yang akan menjadi acuan pendeteksian. Setelah mendapatkan garis acuan maka langkah selanjutnya adalah melakukan ujicoba terhadap sampel video kondisi lalu lintas yang telah didapatkan untuk melihat kinerja dari algoritma tersebut. Tahapan tersebut dapat dilihat pada gambar 1 berikut.

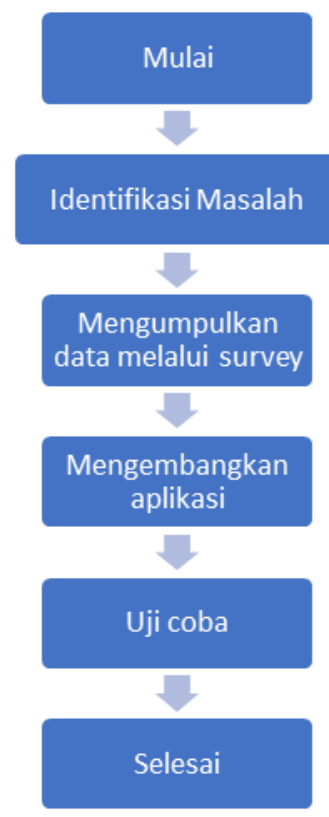

Gambar 1. Perancangan Penelitian

\section{HASIL DAN PEMBAHASAN}

Pada saat ini beberapa tipe kendaaraan bermotor sudah memiliki kamera di bagian depan, namun hanya berfungsi alat bantu saat melakukan parkir dan beberapa produsen peralatan elektronik juga telah membuat alat perekam yang biasa disebut dengan dashcam dan biasa digunakan untuk merekam segala kejadian dalam perjalanan. Sangat disayangkan jika fungsi kamera-kamera yang ada dikendaraan tidak ditingkatkan manfaatnya untuk keamanan. 
JURNAL MEDIA INFORMATIKA BUDIDARMA

Volume 5, Nomor 1, Januari 2021, Page 164-169

ISSN 2614-5278 (media cetak), ISSN 2548-8368 (media online)

Available Online at https://ejurnal.stmik-budidarma.ac.id/index.php/mib DOI 10.30865/mib.v5i1.2502

\subsection{Tahapan Computer Vision}

Dalam penelitian ini tahapan-tahapan percobaan yang dilakukan adalah:

1. Image acquisition

Pada tahapan ini image mengalami akuisisi melalui kamera dimana image disimpan dalam bentuk digital, dalah penelitian ini hasil dari image acquisition disimpan dalam beberapa format yaitu foto digital (file dengan ekstensi .jpg) dan movie (file dengan ekstensi .mp4) maupun stream feed dari kamera. Hasil dari image acquisition ini akan ditayangkan agar dapat menjalani tahap selanjutnya.

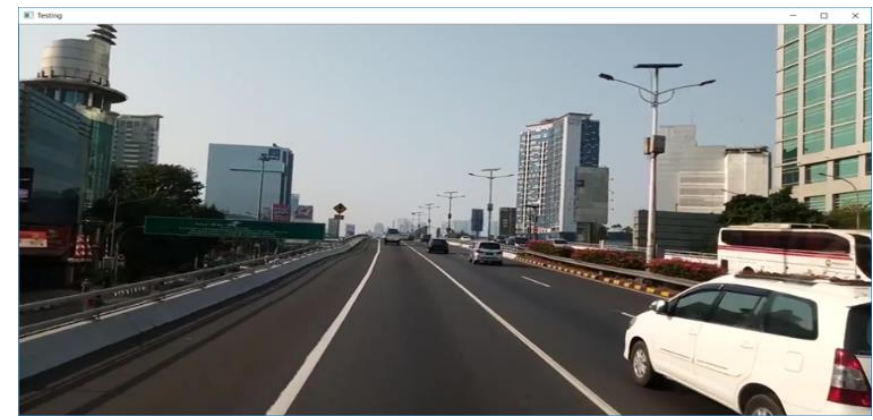

Gambar 2. Hasil Image Acquisition

2. Image segmentation

Tahap selanjutnya adalah image segmentation, dimana pada tahapan ini image yang ada mengalami beberapa proses, proses-proses tersebut yaitu:

a. Konversi dari true color image (red, green, blue) menjadi grayscale.

Pada proses ini kanal-kanal warna RGB dalam tiap pixel image akan dijumlah dan dirata-ratakan untuk menghasilkan image grayscale seperti persamaan dibawah ini.

$$
f_{o=\frac{f_{i(R)}+f_{i(B)}+f_{i(G)}}{3}}
$$

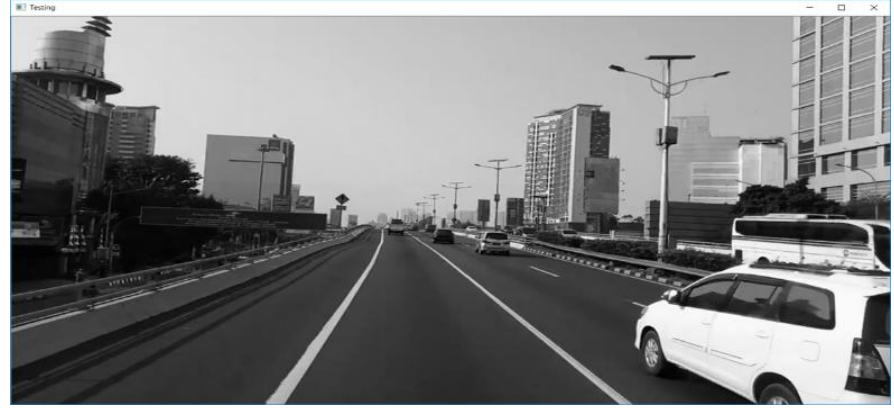

Gambar 3. Grayscale Image

b. Penyebaran spektrum grayscale agar lebih halus dengan menggunakan algoritma Gaussian.

c. Hasil penebaran spektrum grayscale pada tiap pixel akan dibandingkan untuk mendeteksi tepi objek proses ini menggunakan algoritma canny edge detection, objek akan terdeteksi karena perbedaan grayscale yang sangat signifikan

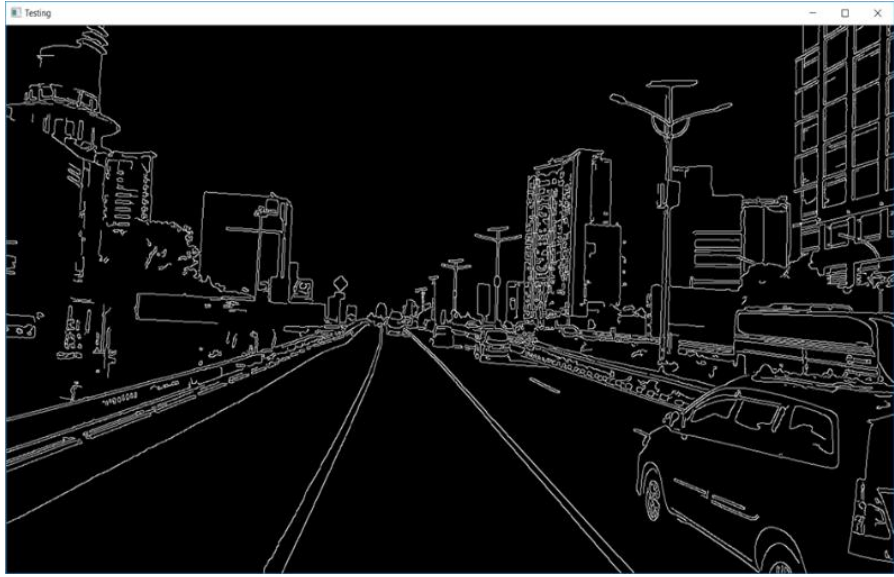

Gambar 4. Hasil Pendeteksian Tepi Objek 
JURNAL MEDIA INFORMATIKA BUDIDARMA

Volume 5, Nomor 1, Januari 2021, Page 164-169

ISSN 2614-5278 (media cetak), ISSN 2548-8368 (media online)

Available Online at https://ejurnal.stmik-budidarma.ac.id/index.php/mib

DOI 10.30865/mib.v5i1.2502

d. Penentuan area of interest dimana bagian image akan mengalami segmentasi, dimana hanya area terpilih yang akan di proses. Dan untuk menentukan area yang akan diproses, maka pixel dalam image disusun dalam sebuah diagram, sehingga dapat menentukan koordinat dari daerah yang akan diproses.

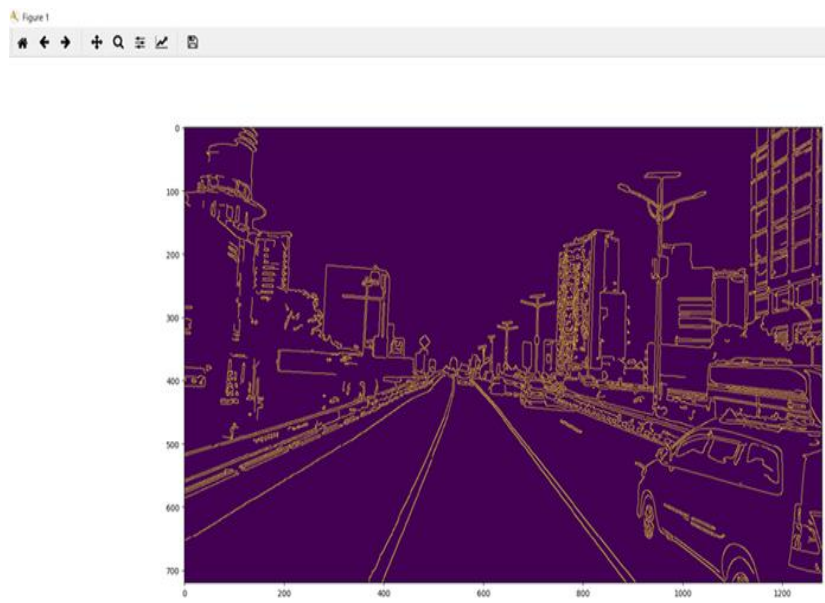

Gambar 5. Diagram yang berisi pixel

d. Setelah menentukan koordinat-koordinat yang menjadi area of interest maka, perlu dibentuk sebuah masking yang bentuknya merupakan sebuah polygon dari koordinat-koordinat yang telah ditentukan sebelumnya.

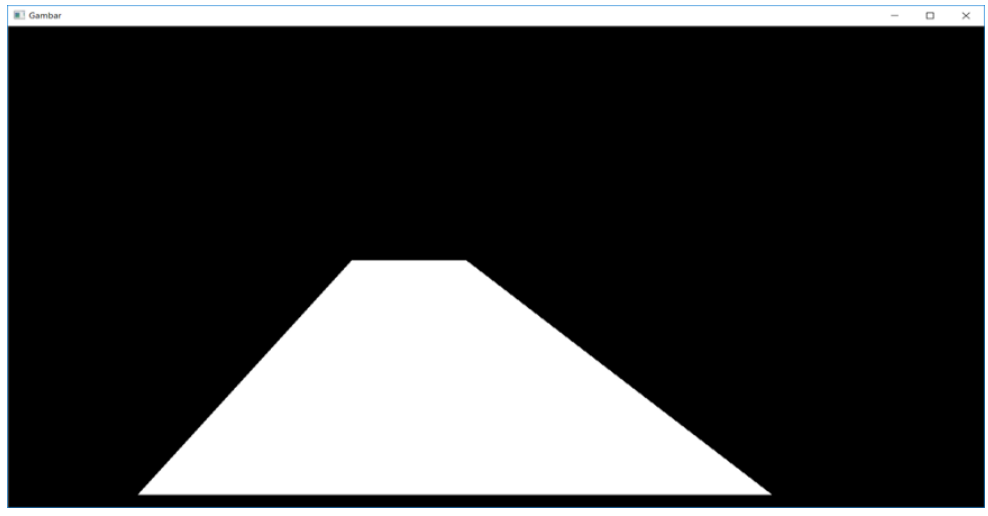

Gambar 6. Polygon yang menjadi masking

e. Setelah masking telah dibentuk maka image yang telah mengalami pendeteksian tepi digabungkan dengan masking yang telah dibentuk dengan operasi bitwise and, proses ini berguna untuk menghilangkan pixelpixel yang tidak perlu dalam proses Image understanding.

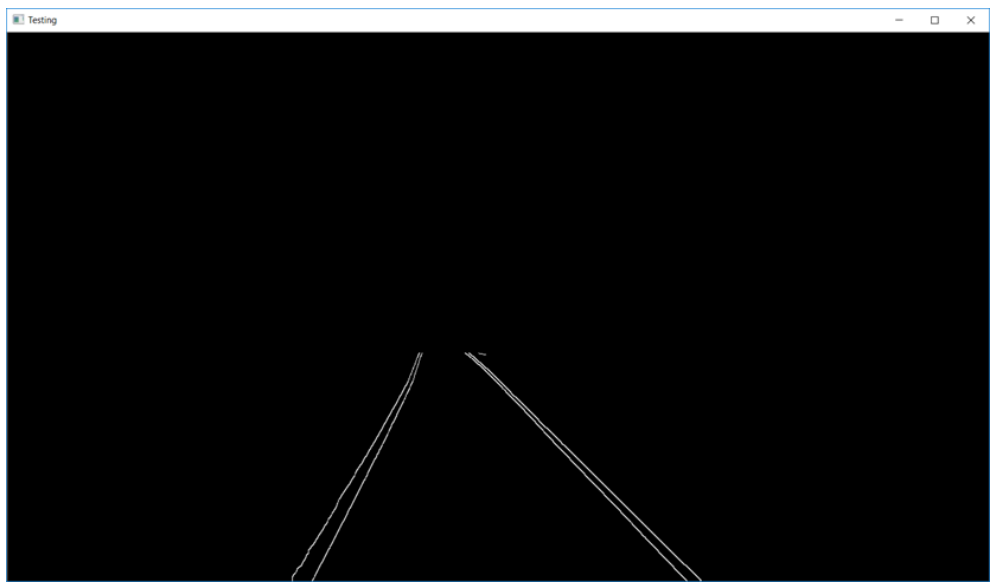

Gambar 7. Implementasi Masking pada Image

Ratna Salkiawati, Copyright (C)2021, MIB, Page 167 
JURNAL MEDIA INFORMATIKA BUDIDARMA

Volume 5, Nomor 1, Januari 2021, Page 164-169

ISSN 2614-5278 (media cetak), ISSN 2548-8368 (media online)

Available Online at https://ejurnal.stmik-budidarma.ac.id/index.php/mib DOI 10.30865/mib.v5i1.2502

\section{Image understanding}

a. Pada tahap ini garis batas yang terdeteksi pada image dipilih pixel yang paling tinggi dan paling rendahnya untuk menentukan koodinat awal dari garis-garis pendeteksi jalus lalu lintas, dan jika sudah ditentukan maka garis-garis tersebut di cantumkan dalam image.

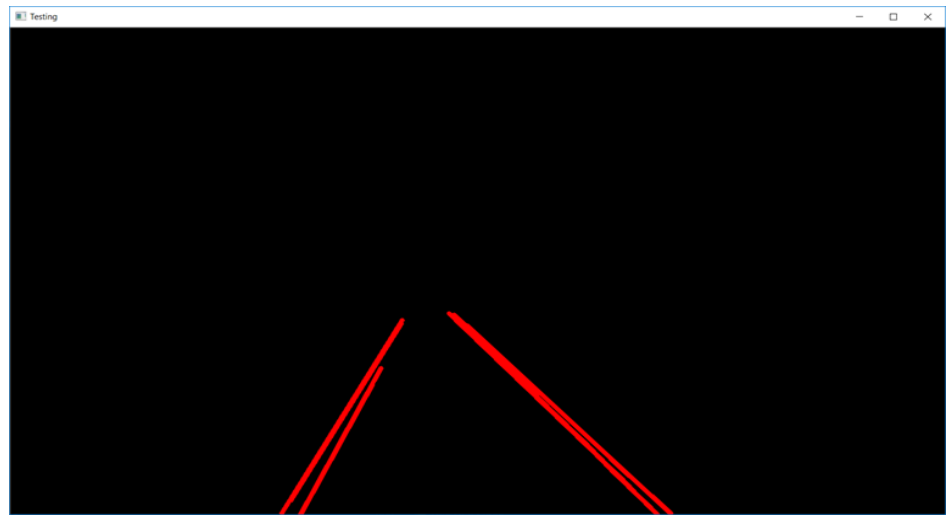

Gambar 8. Garis-garis yang terbentuk dari hasil pendeteksian tepi

b. Pada tahap ini garis-garis hasil deteksi tepi objek yang terbentuk sangat banyak, dan untuk meningkatkaan akurasi pendeteksian, maka koordinat pixel pembentuk garis tersebut harus dirata-ratakan untuk menghasilkan garis pendeteksian yang lebih akurat.

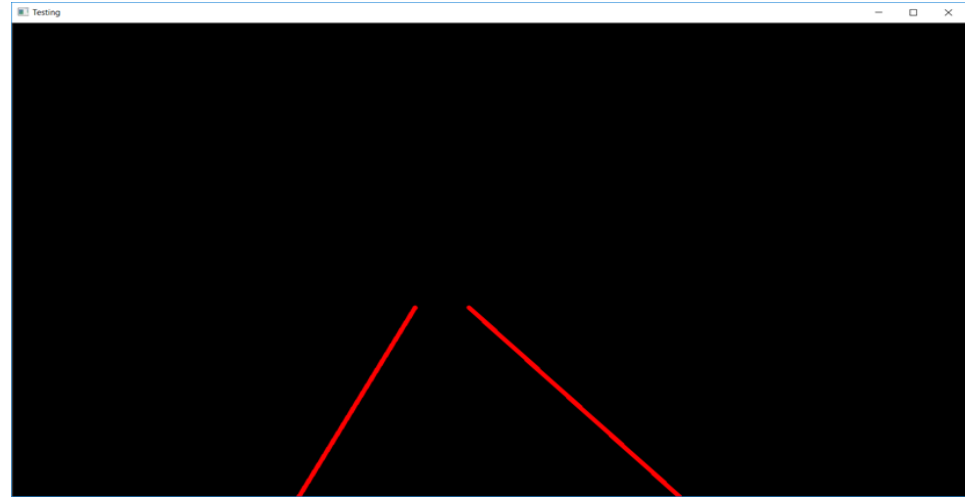

Gambar 9. Garis hasil rata-rata

c. Setelah garis pendeteksian sudah terbentuk, maka langkah terakhir adalah, menggabungkan True colour image dengan garis peneteksian.

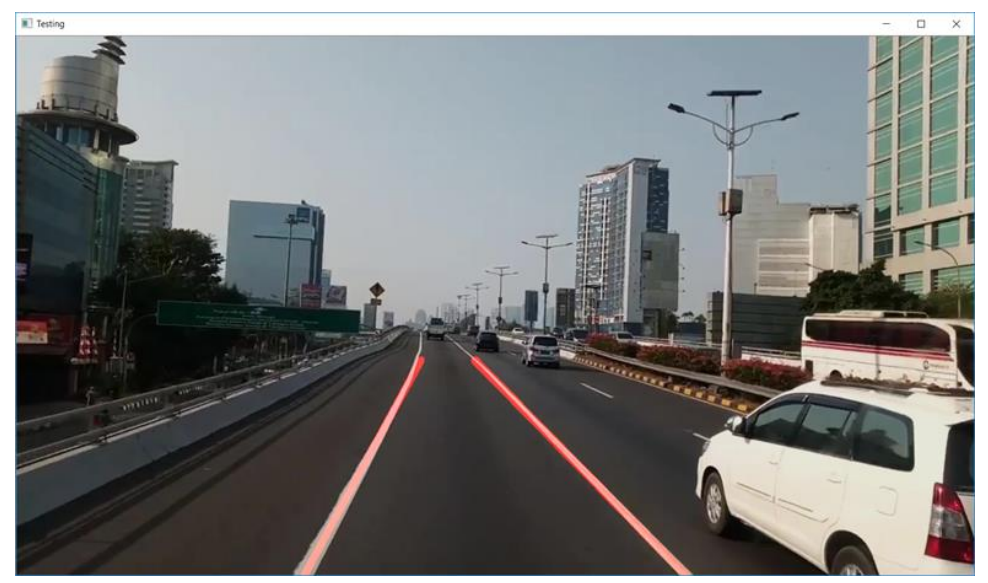

Gambar 10. Hasil Penggabungan True Colour dengan Garis Pendeteksi

d. Dari pendeteksian garis maka langkah selanjutnya koordinat yang membentuk garis ditentukan parameter luar dan dalamnya guna menentukan posisi garis, apakah sudah keluar dari ROI atau tidak, jika garis keluar atau tidak terseteksi didalam ROI maka system akan memberikan signal pada speaker atau buzzer untuk memberikan peringatan kepada pengemudi. 
e. Tahapan selanjutnya model yang telah dibangun diuji terhadap beberapa 100 gambar maka didapatkan didapatkan tingkat efektifitas penggunaan algoritma tersebut sebagai berikut;

Tabel 1. Jumlah Jalur terdeteksi dan tidak terdeteksi

\begin{tabular}{cc}
\hline Jalur Terdeteksi & Jalur Tidak Terdeteksi \\
\hline 78 & 22 \\
\hline
\end{tabular}

\section{KESIMPULAN}

Dengan merubah image yang diperoleh baik dalam bentuk, image, video dan real feed dari kamera yang mengalami proses grayscaling yang dilanjutkan dengan pendeteksian tepi objek dapat menentukan posisi ROI (Region Of Interest) dan dari ROI yang terbentuk maka dapat ditenkuna para meter luar dan dalam dari alur lalu lintas. Hasil pendeteksian jalur lalu lintas dapat dihubungkan dengan buzzer untuk memberi peringatan kepada pengemudi apakah kendaraan yang dikendarainya berada pada jalur yang benar atau tidak. Dan jika kendaraan keluar dari jalurnya maka sistem akan memberikan peringatan kepada pengemudi berupa suara. Dalam penelitian ini pendeteksian jalur lalu lintas akan mengalami kendala, jika gambar yang diproses memiliki kondisi sebagai berikut; garis yang akan dideteksi dalam keadaan kotor, keadaan malam hari dan jalan yang dideteksi tidak memiliki jalur lalu lintas dan untuk itu perlu ditambahkan metode lain yang lebih baik untuk melakukan pendeteksian alur lalu lintas.

\section{UCAPAN TERIMAKASIH}

Kami mengucapkan terima kasih pada segenap instansi terkait dengan penelitian kami ini. Di sini kami berterimakasih pada:

1. Universitas Bhayangkara Jakarta Raya yang telah memberi dukungan dana penelitian pada kami.

2. Instansi kepolisian, khususnya divisi lalu lintas yang mendukung penelitian kami ini.

\section{REFERENCES}

[1] N. F. Ardiansyah, A. Rabi', D. Minggu, and W. Dirgantara, "Computer Vision Untuk Pengenalan Obyek Pada Peluncuran Roket Kendaraan Tempur,” JASIEK (Jurnal Apl. Sains, Informasi, Elektron. dan Komputer), vol. 1, no. 1, pp. 28-37, 2019, doi: 10.26905/jasiek.v1i1.3142.

[2] I. H. Setiadi and Y. H. P, "Lintas Menggunakan Image Processing Dengan Metode Background Subtraction Pada," pp. $1-8$.

[3] E. R. Swedia, M. R. D. Septian, and M. Cahyanti, “Aplikasi Pendeteksi Rambu Lalu-Lintas Menggunakan Operator Sobel dan Metode Hamming," pp. 5-8, 2017.

[4] M. Feniche and T. Mazri, "Lane detection and tracking for intelligent vehicles: A survey," Proc. 2019 Int. Conf. Comput. Sci. Renew. Energies, ICCSRE 2019, pp. 1-4, 2019, doi: 10.1109/ICCSRE.2019.8807727.

[5] V. Q. Nguyen, C. Seo, H. Kim, and K. Boo, "A study on detection method of vehicle based on lane detection for a driver assistance system using a camera on highway,” 2017 Asian Control Conf. ASCC 2017, vol. 2018-January, pp. 424-429, 2018, doi: 10.1109/ASCC.2017.8287207.

[6] N. Ma, G. Pang, X. Shi, and Y. Zhai, “An All-weather Lane Detection System Based on Simulation Interaction Platform,' IEEE Access, vol. PP, pp. 1-1, 2018, doi: 10.1109/access.2018.2885568.

[7] X. Yan and Y. Li, "A method of lane edge detection based on Canny algorithm," Proc. - 2017 Chinese Autom. Congr. CAC 2017, vol. 2017-January, pp. 2120-2124, 2017, doi: 10.1109/CAC.2017.8243122.

[8] A. Mahmoud et al., "Real-time lane detection-based line segment detection," 2018 New Gener. CAS, NGCAS 2018, pp. 57-61, 2018, doi: 10.1109/NGCAS.2018.8572124

[9] G. Ganchimeg and L. Helmut, "Vision based vehicle monitoring at road intersections," Int. Conf. Electron. Inf. Commun. ICEIC 2018, vol. 2018-January, pp. 1-4, 2018, doi: 10.23919/ELINFOCOM.2018.8330568.

[10] S. Shirke and C. Rajabhushanam, "A study of lane detection techniques and lane departure system," 2017 Int. Conf. Algorithms, Methodol. Model. Appl. Emerg. Technol. ICAMMAET 2017, vol. 2017-January, pp. 1-4, 2017, doi: 10.1109/ICAMMAET.2017.8186654.

[11] L. Yuan and X. Xu, "Adaptive Image Edge Detection Algorithm Based on Canny Operator," Proc. - 2015 4th Int. Conf. Adv. Inf. Technol. Sens. Appl. AITS 2015, no. 2, pp. 28-31, 2016, doi: 10.1109/AITS.2015.14.

[12] A. Andrew, J. L. Buliali, and A. Y. Wijaya, "Deteksi Kecepatan Kendaraan Berjalan di Jalan Menggunakan OpenCV," J. Tek. ITS, vol. 6, no. 2, 2017, doi: 10.12962/j23373539.v6i2.23489.

[13] A. Zalukhu, "Implementasi Metode Canny Dan Sobel Untuk Mendeteksi Tepi Citra," J. Ris. Komput., vol. 3, no. 6, pp. $25-29,2016$

[14] R. T. Jurnal, "Implementasi Metode Deteksi Tepi Canny Pada Objek Sebagai Model Keamanan Aplikasi Pada Smartphone Android," Petir, vol. 9, no. 1, pp. 16-20, 2019, doi: 10.33322/petir.v9i1.187.

[15] N. B. Tsani and H. Harliana, "Implementasi Deteksi Tepi Canny Dengan Transformasi Powerlaw Dalam Mendeteksi Stadium Kanker Serviks," J. Ilm. Intech Inf. Technol. J. UMUS, vol. 1, no. 01, pp. 22-33, 2019, doi: 10.46772/intech.v1i01.35. 